\section{Reviving and reclaiming our native food system: Leadership experiences of a research project's community advisory board}

\author{
Rhonda Bowers (Northern Arapaho)* \\ Chair, Growing Resilience Community Advisory Board \\ Pat Harris (Northern Arapaho) \\ Co-chair of the CAB \\ Clarisse Harris (Northern Paiute) \\ Secretary of the $\mathrm{CAB}$
}

Kathryn Lone Fight (Eastern Shoshone)

CAB Member

Ina Weed (Eastern Shoshone)

CAB Member

Nelson Pat White (Northern Arapaho)

CAB Member
Special JAFSCD Issue

Indigenous Food Sovereignty in North America

\section{Swette Center for Arizona State University}

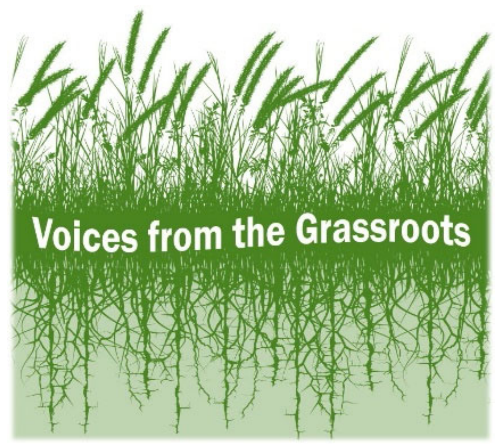

Submitted March 28, 2019/ Accepted March 29, 2019 / Published online October 15, 2019

Citation: Bowers, R., Harris, P., Harris, C., Lone Fight, K., Weed, I., \& White, N. P. (2019). Reviving

and reclaiming our native food system: Leadership experiences of a research project's community

advisory board. Journal of Agriculture, Food Systems, and Community Development, 9(Suppl. 2), 13-17.

https://doi.org/10.5304/jafscd.2019.09B.002

Copyright (C) 2019 by the Authors. Published by the Lyson Center for Civic Agriculture and Food Systems. Open access under CC-BY license.

\begin{abstract}
A s proud Native community leaders who call A the Wind River Reservation home, our battles for sovereignty and respect are not just part of a long-ago history. Claiming our self-empowerment and putting it to good use on behalf of our entire community are challenged more often than we care to recount. In the matter of sustainable food

\footnotetext{
* Rhonda Bowers, chair of the Growing Resilience CommuReservation, Wyoming, USA; rbowers@uwyo.edu
} nity Advisory Board (CAB) (Northern Arapaho), Wind River
\end{abstract}

security, those of us who agreed to serve as members of the Growing Resilience Community Advisory Board (CAB) were reminded of such events. Our CAB was established in 2016 as an oversight group for community wellbeing for a University of Wyoming (UW)-initiated and National Institutes of Health (NIH)-funded research project on gardening and health.

Our history on this 2.2-million-acre $(890,000$ hectare) reservation in north-central Wyoming is 
deeply rooted in the fact that this is the only reservation in the country to have been established for two tribes: the Northern Arapaho and the Eastern Shoshone (which were warring tribes when first forced to live here together). Of the nearly 27,000 people living here today, about 5,000 Eastern Shoshone and 10,000 Northern Arapaho are enrolled tribal members. When looked at by numbers alone, we're a diverse community, but comparisons between the tribes, along with the socio-political issues that arise as we embrace relationshipbuilding of all kinds, tends to polarize views of these sovereign nations and the Wind River Reservation overall. As individuals, many of us feel as though our personal identities, and our contributions, can get lost in the fray.

Like other indigenous groups, the Northern Arapaho and Eastern Shoshone people of the Wind River Reservation have long been targets for research, philanthropy, and judgment. Some of it has been helpful as we continue to battle the legacy of internment, work to claim our rights, and reclaim our traditions, heritage, and culture as we define them. But much of what has been brought to us or imposed on us has been harmful to varying degrees-and in recent times, very often by a lack of recognition and utilization of our own hardearned, community-based expertise and leadership.

In 2011, a research project of a type that was new to us at the time (we were told it was community-based participatory research) received joint-tribal council approval to designate the Wind River Reservation as one of the project's five community partner sites that would spend the next five years studying community efforts to improve food security and food sovereignty. The Food Dignity research project was offered through a U.S. Department of Agriculture's Agriculture and Food Research Initiative (USDA AFRI)-funded grant received by UW, and for the first time any of us could remember, it was our knowledge, our stories, our experiences, and our work as we saw it that would be supported and valued.

Blue Mountain Associates (BMA), a Northern Arapaho-led, local nonprofit health organization known for its commitment to working equally with both the Northern Arapaho and Eastern Shoshone tribes, served as the community leader on the Food
Dignity project. Their implementation of the project included the creation of a community advisory board; the distribution and support of food systems-related minigrants; the expansion and management of farmers markets; the two-year collaboration on Wyoming's first statewide community food summits; and the photographing and video- and audio-recording of a wide variety of community stories about our tribal history of food and food insecurity.

Through the Food Dignity project, Native community members served as activists and leaders, reviving and reclaiming our native food system. Gardeners, farmers, health workers, and entrepreneurs became more visible to outside agencies and funders, as well as to food systems activist groups across the country. We sat on the BMA advisory board that solicited, reviewed, and distributed minigrants to community members who were passionate about being part of the movement demanding the return of a long-lost healthy food system we should be in charge of.

As the Food Dignity project came to a close, its principal investigator, Christine Porter from UW, developed the Growing Resilience research project that was funded in 2015 by NIH as a fiveyear randomized control trial to study the health effects of gardening on 100 Wind River Reservation Eastern Shoshone and Northern Arapaho families who were new to growing fruits and vegetables in their own home gardens. BMA community-based staff help the families plan, build, and grow their gardens, and UW team members gather information about the health impacts of these gardens and the overall project itself. The Growing Resilience CAB was written into the project proposal to oversee the work of both UW and BMA, particularly in regard to how the project serves the wellbeing of the community.

Those of us who were asked to serve on the Growing Resilience CAB saw it as an opportunity to help improve our food supply and food system. We were invited to join in a variety of ways. Gayle Woodsum of Action Resources International in Laramie, Wyoming, who serves as the community liaison for the $\mathrm{CAB}$, invited many of us as a result of her work in a similar role with the Food Dignity project. She also asked for recommendations from 
Native community leaders. She told us at the outset that she was primarily interested in seeing a balanced representation between Northern Arapaho and Eastern Shoshone community members, with a mix of experienced and emerging community leaders among them to lead the CAB. By recommendation, an agency representative from the reservation-based UW Extension office and one from Indian Health Services also accepted invitations to join the CAB.

This was a research project that would not only result in data that were health-related and valuable to the community, but would also end up developing 100 new gardening families who cared about where their food came from and how it could contribute to improved health. Serving as leaders overseeing the community benefit and value potential of the project meant much more to us than limiting our vision to the confines of the research being conducted. Right from the start, we saw the Growing Resilience CAB as a way to be part of bringing back what was lost as a result of what colonizers took from us. When our people were forced onto the Wind River Reservation, we were denied sovereignty over our own food system - the government took away all of our healthy, traditional foods. Those original crimes against us became worse over time. What had once been our tradition of balanced diets coming from the land around us was replaced by artificial, processed, and cheap foods. That non-Native way of feeding us continues today as evidenced by governmental commodity giveaways that include processed meals, candy, and soda.

When each of us agreed to serve on the Growing Resilience $\mathrm{CAB}$, we did so to make a difference, not just for the five years of the research project itself, but in service to a vision of longterm, sustainable food security for our community. We were interested in seeing community food systems work extend beyond time-limited research projects and be led by our own community members. We looked forward to being kept informed of the progress of what would be a very large research project involving many community members who would participate intensely for years as they learned how to garden at their homes and would undergo regular health data collection checks and personal interviews to help determine the impact of those gardening projects on their health and their lives.

It felt like an honor to have the opportunity to stay informed about the details of the project and to be available to hear any questions or concerns of the community that we would then work to address. The Wind River Reservation, in the past, has experienced research as being a process of taking our experiences from us and putting them out into the world in a way that was exploitive and even inaccurate. Our role as CAB members charged us with being certain the participants and the entire community were being served well by being involved in the Growing Resilience research project.

As the $\mathrm{CAB}$ gathered to meet early on in the project's implementation, we were stunned to learn that our reasons for agreeing to serve and the hopes we had for what we could be part of building did not line up with how we were first received and treated. At the outset, the composition of the board was questioned by other Growing Resilience project team members. They wondered whether there was enough diversity of tribal representation among us and whether we had the right experience to successfully serve the CAB. The biggest concern of all came from some project team members who were upset to learn that the $\mathrm{CAB}$ would conduct our own meetings without other team members present. We wondered if rather than it being appreciated that we, as community leaders, had something important to contribute, our role as described in the project proposal and as it has been explained to us was actually going to be taken seriously.

Nevertheless, in our early meetings as a group, we were excited about helping to guide the Growing Resilience project as it began to track our community's health concerns through the lens of home gardening. We drafted questions for the research team to gather information on how the gardens were progressing and how the participants were doing with them. At the same time, we talked about how we wanted the CAB's decision-making to work and quickly agreed with each other that we were committed to the idea that one of the primary goals of the group-beyond ensuring that the community was being served well by the Growing Resilience project-was to create supportive and 
educational food system programs that would continue to operate long after the research project was over. We wanted to set up a community network that would provide ongoing support to the 100 gardeners who would come from participating in the project.

At one of our earliest meetings, one of the $\mathrm{CAB}$ members remarked on how pleased she was that the group was made up of a majority of local Native community members, which was rarely the case in similar projects. She respectfully turned to the two agency representatives and told them she meant no disrespect to them or their membership in the group. Within hours of the close of that meeting, both agency representatives tendered their written resignations from the $\mathrm{CAB}$ without stating reasons for doing so.

That meeting was followed by an explosive few weeks, during which we heard through gossip that the resignations had been tendered because the white members of the group had felt they were victims of reverse racism. We were told by some community leaders that we had jeopardized good relationships that had been going on for years. We were confused and distressed by what felt like unreasonable reactions that were disrespectful of us. The feelings were compounded at the next meeting at which we requested that all Growing Resilience project team members be present. At that time, we presented our list of questions about how the project was going: how were the gardens doing and how were the participants feeling about things? In order to fulfill our project oversight role, we wanted details about project implementation. But instead of the kind of information we sought, we were told that due to confidentiality issues, we would not be given any details about participants or the status of their gardens.

We were stunned and frustrated. We'd been charged with ethical oversight, yet we would not be trusted with anything the researchers deemed confidential. And their list of what couldn't or would not be shared was very long. In addition to our not being permitted to know who any of the participants were, we wouldn't be allowed to see the gardens they were being given and helped to grow, given details on whether or not individual gardens were being successful, nor given any information on how participants felt about the success or failure of their gardens and if they felt as if they needed more help in learning how to garden.

Yet we were told it was fine for community members, including research participants, to come to us on their own with any concerns or questions they might have. Our contact information would be provided to them by the research team, we were told. This meant we had no way of developing trust with the participants unless the research team informed them of us, although the researchers or other team members could be the very people they might want to question or complain about. It was as if the project administrators hadn't really been planning on using us. We needed to push back. We felt we were not supposed to think or ask questions, and that we were being belittled, but we just kept moving ahead.

There we were, giving of our time and expertise on tribal and community history, gardening, and community leadership, and yet it was as if we were digging into information that didn't concern us. All we wanted and expected was to be treated as equal human beings, and it suddenly felt as if those in control of running the project thought we weren't on the same level as them. It was as if they wanted the project to be purely scientific and that making it safe and helpful at the community level didn't matter anywhere near as much.

We wanted to bring heart into every aspect of the project, both as $\mathrm{CAB}$ members and as members of the community. But we began to have the sense that we were just meant to rubber-stamp what the research team wanted to have done. When we pushed back against the notion of being treated like puppets and continued asking for necessary information on the progress of the project, it caused problems for everyone.

But we had each other. We were determined to own and use our self-empowerment. We believed in the idea of this project, and we believed it could be valuable if it also were led by a vision of becoming something sustainable long after the research was completed and its findings were published. We changed the original concept that the $\mathrm{CAB}$ would only meet a couple of times a year and began to conduct monthly meetings. We've added two new Native community leaders to the CAB member- 
ship. We kept asking the questions we wanted answered and didn't shrink when we ran into barriers. Little by little, we found a way to explain that we weren't trying to break confidentiality. We needed the kind of details necessary to be sure the project was going well and a way for project participants to get to know who we were so they would feel comfortable coming to us with questions or concerns.

It took more than a year to create an environment of good communication between the $\mathrm{CAB}$, the garden installation component, and the research component of the project. We stood firm as an independent leadership group with oversight responsibilities. Gradually, the rest of the Growing Resilience team learned how to answer our questions. They held public receptions where community members and project participants interested in meeting us could come to visit and talk.
As a result, we made ourselves a valuable resource for reclaiming sovereignty over our own traditional foods and local food system. We procured the use of land to create a community and educational garden. We have now given presentations twice at the annual national Seeds of Native Health Conference in Minnesota. We sent a representative to attend a Rocky Mountain Tribal Food Sovereignty summit in Montana in 2018 and will be sending two representatives in 2019.

We're using this program to reach large goals — using the Growing Resilience research project and our role as its $\mathrm{CAB}$ - as an open door that can lead to more opportunities for continued self-empowerment for us, all the research project participants, and our entire community, to create a ripple effect for yet more waves of valuable resources to come. 